\title{
EFFECTS OF TRIS (HYDROXYMETHYL) AMINOMETHANE ON THE QUALITY OF FROZEN-THAWED BOAR SPERMATOZOA
}

\author{
Zhao NAMUla ${ }^{1,2}$, Fuminori TANihara ${ }^{1,2^{*}}$, Manita Wittayarat ${ }^{3}$, Maki Hirata ${ }^{1,2}$, \\ Nhien Thi NGUYEN ${ }^{2}$, Takayuki HIRANO ${ }^{2}$, Quynh Anh LE ${ }^{2}$, Masahiro $\mathrm{NII}^{4}$ \\ and Takeshige $\mathrm{OTOI}^{1,2}$ \\ ${ }^{1}$ College of Agricultural Science, Guangdong Ocean University, Guangdong, China; \\ ${ }^{2}$ Faculty of Bioscience and Bioindustry, Tokushima University, Ishii, Myozai-gun, \\ Tokushima 779-3233, Japan; ${ }^{3}$ Faculty of Veterinary Science, Prince of Songkla University, \\ Songkhla, Thailand; ${ }^{4}$ Tokushima Prefectural Livestock Research Institute, Tokushima, \\ Japan
}

(Received 24 July 2018; accepted 20 November 2018)

Tris (hydroxymethyl) aminomethane (Tris) has been used as a $\mathrm{pH}$ regulator for buffering the $\mathrm{pH}$ of dilution extenders for boar semen, such as the Modena extender. The purpose of the present study was to assess the effects of Tris supplementation at different concentrations $(0,8,24$ and $72 \mu \mathrm{M})$ into the freezing extender on the quality and fertilising capacity of frozen-thawed boar spermatozoa. The results showed that the supplementation of $24 \mu \mathrm{M}$ of Tris gave significantly higher percentages of sperm viability and plasma membrane integrity than those of the control group at any time point of assessment $(0 \mathrm{~h}$ and $3 \mathrm{~h}$ post-thawing) $(\mathrm{P}<0.05)$. However, there were no significant differences in the acrosome integrity parameter among the groups. Higher percentages of sperm motility were observed in the spermatozoa cryopreserved with $24 \mu \mathrm{M}$ of Tris compared to the control groups when the samples were analysed $0 \mathrm{~h}$ after thawing $(\mathrm{P}<0.05)$. However, an increase of the Tris concentration to $72 \mu \mathrm{M}$ did not enhance the sperm motility parameters. The total numbers of fertilised oocytes and blastocysts obtained with spermatozoa frozen with $24 \mu \mathrm{M}$ Tris were significantly higher than those of the control group without Tris $(\mathrm{P}<0.05)$. In conclusion, the supplementation of $24 \mu \mathrm{M}$ Tris into the freezing extender contributes to a better boar sperm quality and fertilising capacity after the process of freezing and thawing. Tris

Key words: Boar semen, cryopreservation, $\mathrm{pH}$ regulator, sperm quality,

The use of artificial insemination (AI) in the swine industry has been continuously increasing during the past three decades since it offers several benefits, such as greater efficiency and biosecurity than natural service (Pei et al., 2018).

*Corresponding author; E-mail: tanihara@tokushima-u.ac.jp;

Phone/Fax: 0081 (88) 635-0796 
Long-term preservation of mammalian spermatozoa by freezing has been a very practical tool for furthering AI used in farm animals (Li et al., 2018). Cryopreservation of boar spermatozoa remains a major challenge due to their high sensitivity to cold temperatures because their plasma membrane contains a high proportion of polyunsaturated fatty acids with a low cholesterol content (Cerolini et al., 2001). Cryopreservation can cause damage to spermatozoa leading to unfavourable changes in membrane lipid composition, acrosome status, sperm motility and viability (Gangwar et al., 2018). A number of factors, including fluctuation in osmotic pressure, sperm cold shock, intracellular ice crystal formation, oxidative stress and changes in $\mathrm{pH}$, are thought to influence the cryoinjuries of spermatozoa and their functional maintenance (Isachenko et al., 2003; Soltanpour and Moghaddam, 2013; Gangwar et al., 2018). Semen extenders for freezing, therefore, should contain a cryoprotective agent and energy source and should also be well buffered to prevent changes in $\mathrm{pH}$ and tonicity throughout the preservation period.

The average $\mathrm{pH}$ of freshly ejaculated boar semen should be $7.4 \pm 0.2$, whereas the $\mathrm{pH}$ of commonly used boar semen extenders is approximately 6.8 to 7.2 (Gadea, 2003). A decrease in semen $\mathrm{pH}$ caused by the glycolytic pathway, the main mechanism for sperm energy production, could reduce sperm metabolism and motility (Rigau et al., 1996). Therefore, a substantially controlled slightly alkaline $\mathrm{pH}$ level in the semen extender is necessitated. Tris (hydroxymethyl) aminomethane (Tris) has been used in semen extenders as a $\mathrm{pH}$ regulator (Gadea, 2003). To our knowledge, however, the effects of supplementation of different Tris concentrations into the freezing extender of boar semen have not well been elucidated. The present study was therefore conducted to investigate whether the concentrations of Tris supplemented in the semen freezing extender could affect the quality of frozen-thawed boar spermatozoa as well as sperm penetrability and oocyte development to the blastocyst stage after in vitro fertilisation.

\section{Materials and methods}

\section{Semen collection and preparation}

Semen was collected from four fertile Large White boars (2-3 years old) at the Tokushima Prefectural Livestock Research Institute (Tokushima, Japan), using the 'gloved-hand' technique. Semen samples were diluted threefold with Modified Modena extender, then transported at $25^{\circ} \mathrm{C}$ to the laboratory within $2 \mathrm{~h}$ of collection. The Modified Modena extender consisted of $27.5 \mathrm{mg} / \mathrm{mL}$ D-fructose (Sigma-Aldrich, St. Louis, MO, USA), $6.9 \mathrm{mg} / \mathrm{mL}$ trisodium citrate dihydrate (Wako Pure Chemical Industries, Osaka, Japan), $2.35 \mathrm{mg} / \mathrm{mL}$ ethylenediaminetetraacetic acid disodium salt (Wako Pure Chemical Industries), $1.0 \mathrm{mg} / \mathrm{mL}$ sodium hydrogen carbonate (Wako Pure Chemical Industries), $2.9 \mathrm{mg} / \mathrm{mL}$ citric 
acid monohydrate (Wako Pure Chemical Industries), $5.65 \mathrm{mg} / \mathrm{mL}$ tris (hydroxylmethyl) aminomethane (Tris; Sigma-Aldrich) and $0.2 \mathrm{mg} / \mathrm{mL}$ amikacin sulphate (Meiji, Tokyo, Japan) in distilled water. The diluted semen was centrifuged at $550 \times \mathrm{g}$ for $10 \mathrm{~min}$. After the removal of supernatant, each pellet was diluted to a final concentration of $4 \times 10^{8}$ cells $/ \mathrm{mL}$ with the first base extender that consisted of lactose monohydrate (Wako Pure Chemical Industries), $0.2 \mathrm{mg} / \mathrm{mL}$ amikacin sulphate and $20 \%(\mathrm{v} / \mathrm{v})$ egg yolk in distilled water.

To examine the effects of Tris supplementation during semen freezing on the quality of frozen-thawed spermatozoa, the first extender with various concentrations of Tris was made as follows. The solutions with $0,8,24$, and $72 \mu \mathrm{M}$ of Tris reached an osmolarity of $360 \mathrm{mOsm} / \mathrm{kg}$ by supplementation with varying concentrations of lactose monohydrate $(55-88 \mathrm{mg} / \mathrm{mL})$. The solution with each concentration of Tris was further supplemented with $20 \%(\mathrm{v} / \mathrm{v})$ egg yolk and then centrifuged at $3,000 \times g$ for $30 \mathrm{~min}$. After centrifugation, the supernatant was used for the first extender, in which the osmolarity of the extender was $360 \pm$ $10 \mathrm{mOsm} / \mathrm{kg}$.

\section{Cryopreservation of semen}

Each diluted semen sample was preserved in $15-\mathrm{mL}$ conical polystyrene tubes. To reduce the effects of cold shock on the spermatozoa during the chilling process, the tubes were placed in a $500-\mathrm{mL}$ glass beaker containing $300-350 \mathrm{~mL}$ water at $25^{\circ} \mathrm{C}$, which was then kept in a refrigerator at $5{ }^{\circ} \mathrm{C}$ for $2 \mathrm{~h}$. Before freezing, the second extender (the first extender supplemented with $4 \%[\mathrm{v} / \mathrm{v}]$ glycerol and 1.5\% [v/v] EQUEX STM [Miyazaki Kagaku, Tokyo, Japan]) was added with the half of the first extender. The spermatozoa were then equilibrated at $5{ }^{\circ} \mathrm{C}$ for an additional $5 \mathrm{~min}$. At the end of the equilibration period, the same volume of the second extender was added at $5{ }^{\circ} \mathrm{C}$. The sperm concentration was adjusted to $2 \times 10^{8}$ cells $/ \mathrm{mL}$. The spermatozoa were immediately loaded into 0.25-mL French straws (no. AAA201; IMV, L'Aigle, France). The spermatozoa were frozen by placing the straw $(4 \mathrm{~cm}$ in height from the surface of liquid nitrogen) on a styrofoam plate in liquid nitrogen vapour for $10 \mathrm{~min}$ and subsequently storing it in liquid nitrogen. On the day of examination, the straw was immediately submerged in a $38^{\circ} \mathrm{C}$ water bath for $15 \mathrm{sec}$ for thawing.

Assessment of motility, quality and penetrability of sperm, and oocyte
development

Motility analyses were performed using the computer-assisted sperm analysis (CASA) system (Sperm Class Analyzer ${ }^{\circledR}:$ SCA $^{\circledR}$ v.4.2; MICROPTIC, Barcelona, Spain). The analysis of motility was based on the examination of 25 consecutive digitised images obtained from 3-5 fields using a $\times 10$ phase contrast objective, and at least 500 spermatozoa per sample were analysed using an image 
capture speed of $40 \mathrm{msec}$. Analyses of viability, plasma membrane integrity and acrosome integrity were conducted using a live/dead stain combination (SYBR14/propidium iodide (PI), LIVE/DEAD Sperm Viability Kit; Molecular Probes, Inc., Eugene, OR, USA), the hypo-osmotic swelling test (Ahmad et al., 2003) and fluorescein isothiocyanate-labelled peanut agglutinin (FITC-PNA; Vector Laboratories, Inc., Burlingame, CA, USA), respectively, according to the methods described by Wittayarat et al. (2012). The sperm motility and quality of frozen-thawed spermatozoa were assessed immediately $(0 \mathrm{~h})$ and $3 \mathrm{~h}$ after thawing of semen.

To examine the effects of Tris supplementation during semen freezing on sperm penetrability and oocyte development after in vitro fertilisation (IVF), cumulus-oocyte complexes (COCs) matured in vitro for $44 \mathrm{~h}$ were co-incubated for $20 \mathrm{~h}$ with thawed spermatozoa $\left(1 \times 10^{6}\right.$ cells $\left./ \mathrm{mL}\right)$ according to a previously described method (Do et al., 2015). In the quality assessment of frozen-thawed spermatozoa, the $24 \mu \mathrm{M}$ concentration of Tris was found to be most suitable. Therefore, the COCs were co-incubated with thawed spermatozoa that had been frozen with and without Tris $(24 \mu \mathrm{M})$. After co-incubation, some presumptive zygotes were stained with acetic orcein to examine the fertilisation of frozenthawed spermatozoa (Do et al., 2015). The other zygotes were subsequently cultured for 7 days to evaluate their ability to develop to blastocysts with a clear blastocoel and cells.

\section{Statistical analysis}

The mean values of sperm quality were analysed by analysis of variance (ANOVA) tests followed by Fisher's protected least significant difference (PLSD) tests using STATVIEW (Abacus Concepts, Inc., Berkeley, CA, USA). The data were subjected to arcsine transformation before statistical analysis. Percentage data of fertilisation and embryonic development were evaluated using Student's $t$-test. Differences with a probability value $(\mathrm{P})$ of 0.05 or less were regarded as significant.

\section{Results}

Effects of Tris supplementation during semen freezing on the quality of frozen-thawed spermatozoa

The effects of Tris supplementation during semen freezing on the viability, plasma membrane integrity and acrosome integrity of frozen-thawed spermatozoa are shown in Table 1. Treatment of boar spermatozoa with $24 \mu \mathrm{M}$ of Tris during freezing significantly increased the sperm viability and plasma membrane integrity at $0 \mathrm{~h}$ post-thawing compared to the other groups $(\mathrm{P}<0.05)$. At $3 \mathrm{~h}$ post-thawing, a significantly higher viability was observed in the case of $24 \mu \mathrm{M}$ 
Tris supplementation compared with the $8 \mu \mathrm{M}$ Tris supplemented group and the control group $(\mathrm{P}<0.05)$. Moreover, the percentage of plasma membrane integrity of frozen-thawed spermatozoa supplemented with $24 \mu \mathrm{M}$ Tris was significantly higher than that of the other groups $(\mathrm{P}<0.05)$. There were no significant differences in the acrosome integrity parameter at any time point $(\mathrm{P}>0.05)$.

\section{Table 1}

Effects of supplementation of tris (hydroxymethyl) aminomethane (Tris) during semen freezing on the viability, plasma membrane integrity and acrosome integrity of frozen-thawed boar spermato-

zoa

\begin{tabular}{|c|c|c|c|c|c|c|}
\hline \multirow{2}{*}{$\begin{array}{l}\text { Tris } \\
(\mu \mathrm{M})\end{array}$} & \multicolumn{2}{|c|}{ Viability (\%) } & \multicolumn{2}{|c|}{ Plasma membrane integrity (\%) } & \multicolumn{2}{|c|}{ Acrosome integrity (\%) } \\
\hline & $0 \mathrm{~h}$ & $3 \mathrm{~h}$ & $0 \mathrm{~h}$ & $3 \mathrm{~h}$ & $0 \mathrm{~h}$ & $3 \mathrm{~h}$ \\
\hline 0 & $23.0 \pm 6.2^{\mathrm{b}}$ & $11.5 \pm 4.7^{\mathrm{b}}$ & $29.3 \pm 2.2^{\mathrm{b}}$ & $22.3 \pm 2.0^{\mathrm{b}}$ & $98.1 \pm 0.2^{\mathrm{a}}$ & $90.8 \pm 1.5^{\mathrm{a}}$ \\
\hline 8 & $23.1 \pm 6.3^{b}$ & $10.6 \pm 4.0^{\mathrm{b}}$ & $29.8 \pm 3.2^{\mathrm{b}}$ & $21.6 \pm 3.0^{\mathrm{b}}$ & $97.9 \pm 0.5^{\mathrm{a}}$ & $91.5 \pm 0.5^{\mathrm{a}}$ \\
\hline 24 & $42.3 \pm 3.2^{\mathrm{a}}$ & $26.5 \pm 5.0^{\mathrm{a}}$ & $37.4 \pm 1.4^{\mathrm{a}}$ & $31.3 \pm 1.0^{\mathrm{a}}$ & $98.5 \pm 0.3^{\mathrm{a}}$ & $93.3 \pm 0.9^{\mathrm{a}}$ \\
\hline 72 & $21.7 \pm 5.1^{\mathrm{b}}$ & $13.7 \pm 5.0^{\mathrm{a}, \mathrm{b}}$ & $29.4 \pm 1.9^{\mathrm{b}}$ & $22.1 \pm 2.1^{\mathrm{b}}$ & $98.3 \pm 0.3^{\mathrm{a}}$ & $91.6 \pm 1.3^{\mathrm{a}}$ \\
\hline
\end{tabular}

The quality parameters of post-thaw spermatozoa from four boars were assessed immediately $(0 \mathrm{~h})$ and $3 \mathrm{~h}$ after thawing of semen frozen with various concentrations $(0-72 \mu \mathrm{M})$ of Tris. Data are expressed as the mean \pm SEM. ${ }^{a-b}$ Values with different superscript letters in the same column at each incubation time differ significantly $(\mathrm{P}<0.05)$

The total and progressive motility values of frozen-thawed spermatozoa treated with Tris at different concentrations are shown in Fig. 1. Supplementation of Tris at $24 \mu \mathrm{M}$ gave significantly higher percentages of total and progressive motility values than those in the other groups $(\mathrm{P}<0.05)$ when the samples were assessed immediately after thawing $(0 \mathrm{~h})$. The total and progressive motilities of sperm treated with $24 \mu \mathrm{M}$ Tris were significantly higher than those of sperm treated with $8 \mu \mathrm{M}$ Tris $(\mathrm{P}<0.05)$ at $3 \mathrm{~h}$ post-thawing. An increase of Tris concentration to $72 \mu \mathrm{M}$ did not enhance the sperm motility parameters after the freezing and thawing processes.

Sperm penetrability and oocyte development to blastocysts using spermatozoa frozen with $24 \mu M$ Tris

Sperm penetrability and oocyte development after in vitro fertilisation with spermatozoa frozen with $24 \mu \mathrm{M}$ Tris are shown in Table 2 . The percentages of the total number of fertilised oocytes and the embryos developed to blastocysts using the spermatozoa frozen with $24 \mu \mathrm{M}$ of Tris were significantly higher than those from spermatozoa frozen without Tris supplementation $(\mathrm{P}<0.05)$. No significant differences in the proportion of monospermic fertilisation and the percentage of cleaved embryos were observed between the two groups $(\mathrm{P}>0.05)$. 

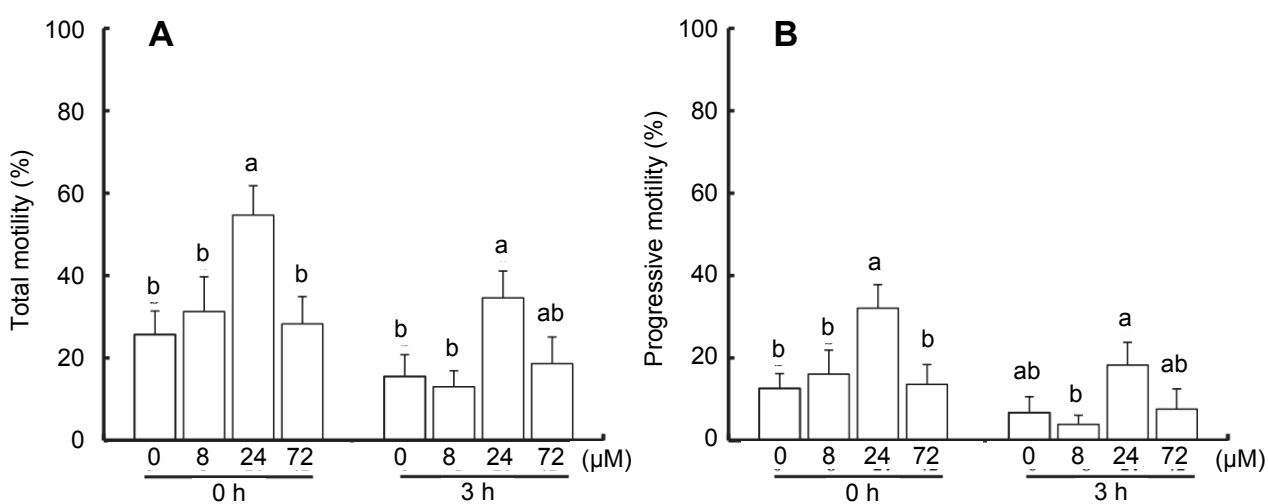

Fig. 1. Effects of supplementation of tris (hydroxymethyl) aminomethane (Tris) during semen freezing on the total motility (A) and progressive motility (B) of frozen-thawed boar spermatozoa. The sperm motility of post-thaw spermatozoa from four boars was assessed immediately $(0 \mathrm{~h})$ and $3 \mathrm{~h}$ after thawing of semen frozen with various concentrations $(0-72 \mu \mathrm{M})$ of Tris. ${ }^{\mathrm{a}-\mathrm{b}}$ Bars with different letters differ significantly $(\mathrm{P}<0.05)$

Table 2

Sperm penetrability and oocyte development after in vitro fertilisation using spermatozoa frozen with tris (hydroxymethyl) aminomethane (Tris)

\begin{tabular}{|c|c|c|c|c|c|c|}
\hline \multirow[b]{2}{*}{ Group } & \multirow{2}{*}{$\begin{array}{c}\text { No. of } \\
\text { oocytes } \\
\text { examined }\end{array}$} & \multicolumn{2}{|c|}{ No. $(\%)$ of oocytes fertilised } & \multirow{2}{*}{$\begin{array}{c}\text { No. of } \\
\text { oocytes } \\
\text { examined }\end{array}$} & \multicolumn{2}{|c|}{ No. $(\%)$ of embryos } \\
\hline & & $\begin{array}{c}\text { Total } \\
\text { fertilisation }\end{array}$ & $\begin{array}{l}\text { Monospermic } \\
\text { fertilisation }\end{array}$ & & Cleaved & $\begin{array}{c}\text { Developed to } \\
\text { blastocysts }\end{array}$ \\
\hline Control & 208 & $36.8 \pm 2.9^{b}$ & $78.1 \pm 2.4^{\mathrm{a}}$ & 314 & $76.9 \pm 3.1^{\mathrm{a}}$ & $2.6 \pm 0.5^{\mathrm{b}}$ \\
\hline Tris & 206 & $46.5 \pm 2.4^{\mathrm{a}}$ & $75.8 \pm 2.3^{\mathrm{a}}$ & 331 & $80.9 \pm 2.3^{\mathrm{a}}$ & $7.0 \pm 0.5^{\mathrm{a}}$ \\
\hline
\end{tabular}

Cumulus-oocyte complexes (COCs) were co-incubated with thawed spermatozoa that had been frozen with $24 \mu \mathrm{M}$ Tris. As control, the COCs were co-incubated with spermatozoa frozen without Tris. The proportions of monospermic fertilisation were calculated by dividing the number of monospermic fertilised oocytes by the total number of fertilised oocytes. Data are expressed as the mean \pm SEM. ${ }^{\mathrm{a}-\mathrm{b}}$ Values with different superscript letters in the same column differ significantly $(\mathrm{P}<0.05)$

\section{Discussion}

To preserve boar spermatozoa for a long period of time until further artificial insemination, sperm cells require an appropriate freezing extender containing a sufficient quantity of nutrients, cryoprotectants, and $\mathrm{pH}$ regulators throughout the time of storage in liquid nitrogen (Gadea, 2003). The $\mathrm{pH}$ of the extracellular fluid, including boar seminal plasma, is known to be tightly regulated and controlled around 7.4 (Gadea, 2003). The semen extender, therefore, should be formulated to closely resemble the environment of sperm cells in the body. Any change in $\mathrm{pH}$ that occurs during the sperm cryopreservation process could affect 
the rates of metabolism, motility and viability of sperm as well as its capability to fertilise the oocytes (Bonato et al., 2012; Zhou et al., 2015). A number of $\mathrm{pH}$ regulators, such as bicarbonate, sodium citrate, Hepes or Tris, have been added into the extender to control the $\mathrm{pH}$ of the medium (Gadea, 2003). Because Tris has a physiological $\mathrm{pH}$ representative of most living cells, is less expensive than any other buffering agents and is highly water soluble, it has become a practical $\mathrm{pH}$ regulator in many mammalian semen extenders that protect against $\mathrm{pH}$ changes by resisting the alteration in hydronium ion and hydroxide ion concentrations.

In the present study, we investigated whether the concentration of Tris has any effect on frozen-thawed boar sperm quality, sperm penetrability and oocyte development to the blastocyst stage. We have found that the supplementation of $24 \mu \mathrm{M}$ of Tris into the freezing extender contributed to a better boar sperm quality after the process of freezing and thawing. Increasing the concentration of Tris to $72 \mu \mathrm{M}$ tended to diminish the rates of sperm viability and plasma membrane integrity. The harmful effect might result from sperm cell toxicity caused by the ease of Tris to penetrate the cell, since it is classified as a highly fat-soluble element that contains a chemically reactive aliphatic amino group (Good et al., 1966), and by the increase of outer membrane permeability resulting from the inductive effect of Tris (Irvin et al., 1981). Excessive concentrations of Tris also reduced the total and progressive sperm motility. This failure of sperm motility may be explained by the interaction of Tris with metal ions in the medium, leading to the restriction in calcium uptake by cell membrane vesicles (Hanlon et al., 1966; Upreti et al., 1995) as well as the inhibition of the respiratory enzymes in mitochondria (Hayashi et al., 1981) which interrupts the production process of utilisable energy (ATP).

Decreasing the concentration of Tris to $24 \mu \mathrm{M}$ would be appropriate to cryopreserve the boar spermatozoa since several parameters, including sperm motility, viability, and plasma membrane integrity were better than in any other groups, and the spermatozoa frozen with Tris at this concentration were also capable of fertilising the oocytes with an acceptable rate of blastocyst development. This indicates that the $\mathrm{pH}$ of sperm freezing extenders is well buffered by $24 \mu \mathrm{M}$ of Tris during the freezing and thawing processes, resulting in an improvement of sperm quality and capability. Sperm cryopreservation is known to elevate intracellular levels of reactive oxygen species (ROS), causing oxidative stressinduced acidosis (Tsai et al., 1997; Schieber and Chandel, 2014; Lucio et al., 2016). Semen with a pH between 5.2 and 6.2 has been found to have lower sperm total motility, progressive motility, hypo-osmotic swelling rate and sperm penetration compared to semen with a $\mathrm{pH}$ between 7.2 and 8.2 (Zhou et al., 2015). To protect the suitable microenvironment conditions for preserved spermatozoa, $\mathrm{pH}$ alkalisation could be induced by Tris, and a Tris concentration of $24 \mu \mathrm{M}$ may be sufficient to compensate for, and overcome, acidosis (Giunti et al., 2007). 
During the process of freezing and thawing, the occurrence of lipid peroxidation caused by the accumulation of ROS and the removal of natural antioxidants in the seminal plasma could severely damage the lipid tails in the sperm plasma membrane, leading to undesirable effects on spermatozoa functions and their penetrability (Bansal and Bilaspuri, 2010). In a previous study, we reported that the supplementation of skim milk powder to the semen extender improves the motility and viability of boar sperm after long-term liquid preservation (Namula et al., 2014). Skim milk has been considered to be a non-enzymatic antioxidant that functions by the sulphhydryl groups (Bustamante Filho et al., 2009). Therefore, supplementation with antioxidants such as skim milk may reduce the impact of oxidative stress during the sperm preservation process and improve the quality of preserved sperm.

In conclusion, a freezing extender supplemented with $24 \mu \mathrm{M}$ of Tris could be used for cryopreserving boar spermatozoa, as its use notably increased the post-thawing motility, viability and plasma membrane integrity of sperm and the blastocyst developmental rate. This finding would be useful for further strategies of boar semen cryopreservation and artificial insemination.

\section{Acknowledgements}

We thank the Nippon Food Packer, K. K. Shikoku (Tokushima, Japan), for supplying the porcine ovaries. This work was supported in part by the Japan Science and Technology Agency/Japan International Cooperation Agency, Science and Technology Research Partnership for Sustainable Development (JST/JICA, SATREPS) and by the Ministry of Education, Culture, Sports, Science and Technology (No.17H03938 and 17K19325).

\section{References}

Ahmad, Z., Anzar, M., Shahab, M., Ahmad, N. and Andrabi, S. M. (2003): Sephadex and Sephadex ion-exchange filtration improves the quality and freezability of low-grade buffalo semen ejaculates. Theriogenology 59, 1189-1202.

Bansal, A. K. and Bilaspuri, G. S. (2010): Impacts of oxidative stress and antioxidants on semen functions. Vet. Med. Int. 2010, pii: 686137. doi: 10.4061/2011/686137.

Bonato, M., Cornwallis, C. K., Malecki, I. A., Rybnik-Trzaskowska, P. K. and Cloete, S. W. (2012): The effect of temperature and $\mathrm{pH}$ on the motility and viability of ostrich sperm. Anim. Reprod. Sci. 133, 123-128.

Bustamante Filho, I. C., Pederzolli, C. D., Sgaravatti, A. M., Gregory, R. M., Dutra Filho, C. S., Jobim, M. I. M. and Mattos, R. C. (2009): Skim milk-egg yolk based semen extender compensates for non-enzymatic antioxidant activity loss during equine semen cryopreservation. Anim. Reprod. 6, 392-399.

Cerolini, S., Maldjian, A., Pizzi, F. and Gliozzi, T. M. (2001): Changes in sperm quality and lipid composition during cryopreservation of boar semen. Reproduction 121, 395-401. 
Do, L. T., Luu, V. V., Morita, Y., Taniguchi, M., Nii, M., Peter, A. T. and Otoi, T. (2015): Astaxanthin present in the maturation medium reduces negative effects of heat shock on the developmental competence of porcine oocytes. Reprod. Biol. 15, 86-93.

Gadea, J. (2003): Review: Semen extenders used in the artificial insemination in swine. Span. J. Agric. Res. 1, 17-27.

Gangwar, C., Saxena, A., Patel, A., Singh, S. P., Yadav, S., Kumar, R. and Singh, V. (2018): Effect of reduced glutathione supplementation on cryopreservation induced sperm cryoinjuries in Murrah bull semen. Anim. Reprod. Sci. 192, 171-178.

Giunti, C., Priouzeau, F., Allemand, D. and Levraut, J. (2007): Effect of Tris-Hydroxymethyl Aminomethane on intracellular $\mathrm{pH}$ depends on the extracellular non-bicarbonate buffering capacity. Trans. Res. 150, 350-356.

Good, N. E., Winget, G. D., Winter, W., Connolly, T. N., Izawa, S. and Singh, R. M. (1966): Hydrogen ion buffers for biological research. Biochemistry 5, 467-477.

Hanlon, D. P., Watt, D. S. and Westhead, E. W. (1966): The interaction of divalent metal ions with tris buffer in dilute solution. Analyt. Biochem. 16, 225-233.

Hayashi, N., Kinemuchi, H. and Kamijo, K. (1981): Effect of tris (hydroxymethyl) aminomethane on amine oxidase activity in dog brain, liver and serum and in human placenta. Jpn. J. Pharm. 31, 737-746.

Irvin, R., MacAlister, T. and Costerton, J. (1981): Tris (hydroxymethyl) aminomethane buffer modification of Escherichia coli outer membrane permeability. J. Bacteriol. 145, 1397-1403.

Isachenko, E., Isachenko, V., Katkov, II, Dessole, S. and Nawroth, F. (2003): Vitrification of mammalian spermatozoa in the absence of cryoprotectants: from past practical difficulties to present success. Reprod. Biomed. Online 6, 191-200.

Li, J., Parrilla, I., Ortega, M. D., Martinez, E. A., Rodriguez-Martinez, H. and Roca, J. (2018): Post-thaw boar sperm motility is affected by prolonged storage of sperm in liquid nitrogen. A retrospective study. Cryobiology 80, 119-125.

Lucio, C. F., Regazzi, F. M., Silva, L. C. G., Angrimani, D. S. R., Nichi, M. and Vannucchi, C. I. (2016): Oxidative stress at different stages of two-step semen cryopreservation procedures in dogs. Theriogenology 85, 1568-1575.

Namula, Z., Kodama, R., Tanihara, F., Morita, Y., Sato, Y., Wittayarat, M., Taniguchi, M. and Otoi, T. (2014): Effects of skim-milk supplementation on the quality and penetrating ability of boar semen after long-term preservation at $15^{\circ} \mathrm{C}$. Acta Vet. Hung. 62, 106-116.

Pei, Y., Yang, L., Wu, L., He, H., Geng, G., Xu, D., Chen, H. and Li, Q. (2018): Combined effect of apigenin and ferulic acid on frozen-thawed boar sperm quality. Anim. Sci. J. 89, 956-965.

Rigau, T., Piedrafita, J., Reverter, A., Canal, M. and Rodríguez-Gil, J. (1996): The rate of L-lactate production: a feasible parameter for the fresh diluted boar semen quality analysis. Anim. Reprod. Sci. 43, 161-172.

Schieber, M. and Chandel, N. S. (2014): ROS function in redox signaling and oxidative stress. Curr. Biol. 24, R453-462.

Soltanpour, F. and Moghaddam, G. (2013): Effects of frozen diluents on storage of ram sperm. Int. J. Adv. Biol. Biom. Res. 1, 1698-1704.

Tsai, K. L., Wang, S. M., Chen, C. C., Fong, T. H. and Wu, M. L. (1997): Mechanism of oxidative stress-induced intracellular acidosis in rat cerebellar astrocytes and C6 glioma cells. J. Physiol. 502 (Pt 1), 161-174.

Upreti, G., Oliver, J., Duganzich, D., Munday, R. and Smith, J. (1995): Development of a chemically defined ram semen diluent (RSD-1). Anim. Reprod. Sci. 37, 143-157.

Wittayarat, M., Kimura, T., Kodama, R., Namula, Z., Chatdarong, K., Techakumphu, M., Sato, Y., Taniguchi, M. and Otoi, T. (2012): Long-term preservation of chilled canine semen using vitamin $\mathrm{C}$ in combination with green tea polyphenol. Cryo Letters 33, 318-326.

Zhou, J., Chen, L., Li, J., Li, H., Hong, Z., Xie, M., Chen, S. and Yao, B. (2015): The semen pH affects sperm motility and capacitation. PLoS One 10, e0132974. 